\title{
Lá Ganadería en la Comunidad de Tupe
}

\author{
POr IOSE MATOS MAR.
}

Enmarcado geográficamente el área cultural del idioma Kauke o Xakaro en el Perú ("Letras" № 44), voy a tratar, ya dentro del informe puramente etnológico acerca de la Ganadería, una de las actividades económicas del grupo.

CARACTEFISTICAS GENERALES.- La ganadería constituye en la Comunidad de Tupe, - Y Yauyos, departamento de Lima - después de la agricultura la principal ocupación de sus habitantes. Así como nadie deja de poseer porciones de tierra, todos son dueños de diversas clases de qanado. Soldmente desde hace 90 a 15 años, está tomando gran auge la ganadería en lac Punaldélan Cemunidad, actuaimente los tupinos arriendan cada año en mayor número los pastos punales, con el fin de criar su ganado. La principal dificultad a este incremento es la falta de gente y lo que llamaríamos la "agresión climática". Los tupinos, que viven $¥ 2830 \mathrm{~m}$. sobre el nivel del mar, todavía no se aclimatan a esta zona frígida $(3.200$ a $4.200 \mathrm{~m}$.). De otro lado tienen que atender a sus cultivos en la parte media y baja de la zona. Dos o tres familias han dejado completamente sus ocupaciones e intereses en la pare media, Tupe, y se dedican ahora exclusivamente a la Puna.

Dentro del área geográfica de la Comunidad existen dos tipos de ganadería:

1.-La ganadería (propiamente dicha), practicada en gran escalà en la Puna, zona frígida, donde constituye la única actividad.

2.- La ganadería en las quebradas de Tupe y Cachuy, en las cuales los animales constituyen los elementos de aprovisionamiento de diversas materias primas como la leche, el cuero, la carne y queso. 
La ganadería en la Comunidad tiene su centro principal en la Puna de Tupe. Antiguamente, hace unos 50 ó 60 años, la usaban los "puneros" gente de los pueblos vecinos, de habla keshwa, especialmente de Huantán, Laraos, Pampas y Cacra, todos ellos distritos vecinos; recién desde 1934 en que surgió un conflicto entre ellos y los comuneros tupinos, estos ú!timos están formando sus "puntas" o rebaños en gran escala.

La principal riqueza ganiadera deniro del área la constituyen los ovejunos, de los que se calcula unas 15 a 20 mil cabezas. Le siguen en importancia los vacunos, auquénidos, caprinos, asnales, mulares, y caballares. A los primeros se les aprovecha de preferencia en su lana, que les sirve tanto para confeccionar sus vestidos, como para venderla y constituir su mayor capital. Manufacturan, especialmente en la Puna, muchos tejidos con los cuales obtienen por trueque productos agrícolas en diferentes regiones. El resto de los animales les sirve para transporte.

Cuidan los animales, hombres, mujeres y niños con especial esmero, diariamente los lievan a pastar y los vigilan sobre todo on su alimentación, dosificándoles su ración diaria, y también evitando que hagan daño a los sembríos.

La propiedad de los animales es particular, por familias; existiendo pequeños y grandes ganaderos, los primeros en el pueblo y los segundos en la Puna.

Existe una serie depSociedades Ganaderase perfectamente instituídas, organizaciones sumamente interesantes y que trascieden más allá de la función propiamente ganadera.

Con la Ganadería hay todo un complejo de fiestas y creencias asociadas íntimamente a ella. Fiestas como la Herranza, la Vaquería, Echada al Cerco, Visita al Corral. Creencias antiguas como la leyenda de los Uchuchullcos, existencia: de conopas, sociedades de culto como la de Akopukio, adoración a los cerros, etc.

TIPOS DE GANA:DO.-En el área geográfica existen los siguientes animales domésticos:

a) En la Puna, (parte alta y zona de mayor importancia): 1, el ovejuno: a la hembra la llaman "borrega" y al macho "carnero". "Huachos" son los que han perdido a su madre. 2, los auquénidos, constituídos por las siguientes especies: las llamas (auchenia lama); a la hembra le llaman "huacada"; al macho: llama. Las alpacas (auchenia pacus), son llamadas "pacos". El cruce de una alpaca con una "huacada", se llama "pacocha" y es más parecida a la alpaca. Los "mishte" (blanco) son los 
cruces de alpaca y llama. El macho de este cruce es la Llama. . Las alpacas a veces también se cruzan con vicuñas hembras. Un "misitte" (crizado) con otro "mishte". es llamado también "mishte". Un "mishte" con alpaca siempre da alpaca. Las pacochas entre si dan pacochas.

3. Las cabras. Chivato orko: el macho. Katso cabra: la hembra.

El cruce de cabra y carnero se llama "calato". Pero estos apenas viven unos dias. Además la puna es campo propicio para el desarrollo de las vicuñas( auchenia vicugna) y venados; debido a que no son molestadas por los cazadores, viven tranquilamente y se reproducen en aburdancia. La cantidad de estas especies es abundante en esta zona. Son especies no domesticadas.

b) En la parte media (quebradas) existen:

1. El ganado vacuno. Toros y vacas; no existen bueyes. A los beCêros les llaman "zete". El nombre de vaca en kauke es "uaka". 2. las oveias. 3. las cahras. 4. el ganado mular. 5. el ganado caballar. La hembra es llamada yegua. 6. el porcino (cuche). Además las siguientes esipezies menores: 1. los perros (xal'ko). 2. los gatos (mishi). 3. las gallinas (uallpa), orko (gallo). Chiuche (pollitos). 4. los cuyes (kúikio). [cavia cobaya].

LA GANADERIA EN LA PUNA.-- Anualmente el día primero de enero la Comunidad de Tupe se reúne para tomar sus principales acuerdos acerca de la marcha del pueblo. Uno de los principales asuntos que se tratan en esta solemne ceremonia es el arriendo de las "canchas, paraderos, estancias o parajes" de la puna.

Los pastos púnales estánc divididos en vestancias o parajes". También se les llama "paraderos o canchas". El arriendo es solamente para los comuneros; hay dos o tres excepciones, personas que tienen posesión de un determinado "paraje" desde muchos años atrás, son gente de fuera, de otra jurisdicción y se les da el nombre de "puneros". Los "paraderos" son de varios tamaños. El arrendamiento es anual y se paga por paraje entre S|. 10.00 á S|. 35.00, según el área. Este año hubo dos parajes vacantes que se remataron en S|. 470.00 a un tupino (llamado rematista) quien a su vez, los alquiló a un punero de otra jurisdicción, debido a que están muy arriba, y son muy grandes, como para 2000 á 3000 cabezas y como no hay tupinos que tengan esa cantidad de ganado, se arrienda a personas de afuera a fin de que no se pierda el pasto. Cada paraje tiene sus pastos, casa o choza y sus corrales. Los "paraderos" que colindan con la propiedad particular en la parte baja se llaman "echaderos". 
Los parajes o paraderos que existen son los siguientes:

En la parte alta, en plena puna:

1 Canllacocha, 2 Huarip culca, 3 Balcón, 4 Ujujui, 5 Chalansuran, 6 Chanua, 7 Huaitacancha, 8 Ahuana, 9 Layampuasi, 10 Millo, 11 Carhuisla, 12 Cerumphuasi, 13 Tacrampe, 14 Yaro, 15 Ayaviri, 16 Bultunya, 17 Pariapampa, 18 Chilimphuasi, 19 Lancato, 20 Pallcagrande, 21 Rodiuna, 22 Andahuacho, 23 Sicla, 24 Ostuna, 25 Arcaicocha, 26 Pallcachico, 27 Ullacai, 28 Tucsa Grande, 29 Cancaushu, 30 Shitcasha, 31 Tucsa chico, 32 Huacaillo, 33 Chaquipata, 34 Quirque, 35 Huacracocha, 36 Chaucas, 37 Cacahuasi. 38 Chaquicocha, 39 Shujlla, 40 Paujaj.

En la parte baja, parajes que se usan para ganado vacuno:

1 Casapata, 2 Yatunhurco, 3 Huisracha, 4 Tambillo, 5 Tayacancha, 6 Pallca.

El arrenáamiento de estos pastos punales constituye el mayor ingreso para la Comunidad. Cerca de $\mathbf{S} \mid \mathbf{1}, 000.00$ son recaudados anualmente, los que se utilizan en diferentes obras de mejoramiento, tales como el Colegio, refacción de caminos, gastos de viaje del personero a Lima, cuando se presenta algún reclamo, etc. El precio señalado a los comuneros es ínfimo debido a que tienen "obligaciones con la comunidad" (así reza en sus acuerdos). Estas obligaciones en primer lugar consisten en el pago del interés anual del dinero que deben a la Comunidad, interés que varía entre. 30 á $40 \%$ sobre los 100 a 500 soles que cada comunero adeuda a la Comunidad.

Para pastar los animales secarriendano anualmente las andenerías que se siembran con maíz, en la quebrada, como Kápia, Uarcusa, Vishka y Kulkuncha, para el "rastrojo de ohalares", es decir que cuando termina la cosecha del maíz, la chala o planta del maíz, es usada para los animales; esto sucede, sobre todo, en época en que los pastos naturales son escasos. El arrendamiento es en remate, un año en una parte, otro año en otra, debido a que esas endenerías se cultivan así, cuesta entre S!. 400.00 á S|. 500.00 cada zona. Acostumbran reunirse dos o tres familias para sacarlas en remate. Estos chalares están ubicados en la parte media de la quebrada de Tupe.

Los arrendamientos anuales de la Comunidad tienen su origen en el año 1934; hasta esa fecha dos o tres tupinos eran los que tenían su ganado en la puna, el resto estaba ocupado por los "puneros" gente de otros pueblos, que usaban los pastos de la comunidad. Estos, hasta esa fecha, iban a Tupe para el Año Nuevo, con leña y carne para pagar sus arrendamientos, otros no lo hacían y el pueblo se veía obligado a nombrar a dos o tres autoridades a fin de hacer los cobros respec- 
tivos, lo cual ocasionaba muchos pleitos y disgustos. Recolectaban por 25 "canchas" o "paraderos" entre 600 a 700 soles, a grandes esfuerzos; muchos tupinos alquilaban todos esos paraderos y los subarrendaban. Pero en 1934, el Iuez de Paz, con el Agente Municipal y Teniente Gobernador, decidieron poner fin a la situación que se había creado; ya que los puneros habían entablado juicio a la Comunidad reclamando esas tierras como suyas y no de la Comunidad y estaban por ganarlo.

Acompañados de siete comuneros y con la anuencia del Presidente de la Comunidad, pidieron del Club de Tiro 3 fusiles. Invadieron las canchas de los puneros, el principal de ellos y cabecilla era un pampino. Ocuparon su estancia y se llevaron su ganado, dando cuenta al pueblo en Asamblea Comunal de lo sucedido, resolviendo repartir el ganado entre los jefes de familia, ciudadanos, (las viudas son conșideradas dentro de los ciudadanos) y les tocó a cada uno de ellos 5 animales: ovejas, llamas y alpacas. Como se suponía que ello iba a traer pleito, acordaron que cada comunero pagara un sol por cada cabeza. Juntaron más de 800 soles. Llegó la Guardia Civil y se entabló un juicio ante la Dirección de Asuntos Indígenas, el punero reclamó la devolución de su ganado y el pueblo inició juicio de desahucio. De no hacer este arrebato los puneros hubieran vencido el juicio, dicen los tupinos, porque tenían dinero, sin dinero ya no pudieron seguirlo y perdieron. En el año de 1944terninć el cleito y túvieton que salir todos los puneros. La puna quedó libre $\longleftarrow$ ahora la gozan ampliamente los tupinos.

Actualmente, segun diversos datos proporcionados por nuestros informantes, se calcula que existe entre auquénidos, ovejunos y caprinos unas 30,000 cabezas. Existen 30 familias tupinas que tienen su ganado en la puria, cada una de ellas tiene su "punta" o manada de ovejunos 600 á 800 , además de las cabras y aunquénidos.

Existen asimismo 27 merinos. proporcionados por el Ministerio de Agricultura, Sección Ganadería, que les sirve para mejorar su ganado. El cruce de un ovejuno con un merino le llaman "cruzado".

En la actualidad están trabajando en la construcción de un bañadero, ubicado en.Sicla. Un funcionario del Ministerio de Agricultura es el encargado de esta obra a la cual concurren todos los tupinos intere sados. Se ha constituído entre ellos una Asociación de Ganaderos de Tupe que vela por el mejoramiento de la ganadería y la satisfacción de sus necesidades. Tienen sus Estatutos y Junta Directiva.

El Ministerio ha proporcionado 800 sacos de cemento para la construcción del bañadero. El bañadero servirá, para preparar un baño con 
una solución de cobre al $1 . \%$, con el objeto de exterminar las garrapatas del ganado ovejuno y de los auquénidos. Consistirá, cuando esté terminado: de un corral, la entrada de piso de cemento, -- que es un callejćn donde pasa, uno a uno, el ganado -, el bañadero y el secadero. El animal será bañado durante un minuto y luega pasará al se. cadero, también de piso de cemento, durante unos 10 a 15 minutos. Diariamente, de 9 a $12 \mathrm{~m}$., se podrá bañar unos 3,000 ovejunnos. El coral estará dividido en dos partes con capacidad cada uno de 400 borregas. El bañadero tendrá dos metros de profundidad. Para la entrada y salida del ganado se usarán ganchos especiales.

Los garaderos de la puna utilizan de sus animales la lana y la carne. Más la primera que la segunda. Anualmente, durante los meses de febrero y marzo, trasquilan sus ovejas y a esto le llaman la "cosecha de las ovejas". Lo hacen rápidamente para vender la lana ya sea en el lugar, a los que vienen desde Huancayo, o ellos mismos la llevan hasta esa ciudad; pero generalmente, en, el puente a Chongos, provincia de Huincayo, las venden en la Agencia de la Fábrica de Tejidos "La Andina". La trasquila o cosecha de alpacas es de agosto a setiembre y para su venta siguen el mismo procedimiento que en la anterior.

L.a mayor producción de lana es la de los ovejunos, siguiendo en importancia la de alpacas, las hembras y machos rinden buena cantidad. Las llamas machos son usadas para carga y las hembras para la reproducción más que para da dana. Ha dana dè alpaca ses vende por vellones, y la de borrega por peso. Un vellón corresponde a medio cuerpo de trasquila y comprende el costado derecho o izquierdo del animal. El vellón de alpaca cuesta entre 25 a 40 soles, según el largo, o sea el crecimiento de la lana, cuanto más largo es mejor pagan mejores precios, no se fijan en su calidad. La lana de oveja se vende al peso, por quintales. El quintal de lana de oveja (lana de 20 ovejas) se vende a $S_{1} \cdot 150.00$. A veces venden por vellones la lana del borrega y cuesta entre 4 a 8 soles.

La carne es aprovechada principalmente para satisfacer sus necesidades alimenticias, especialmente hacen de ella charqui o chalona; apenas muerto el animal le echan zal, para una oveja $2 \mathrm{k}$. de sal, para una alpaca $4 \mathrm{k}$., lo cortan en trozos y lo hacen secar. Todos los días comen carne en caldo y en asado. Cocinan con leña de kisuar, de preferencia $y$ con el excremento del gunado: la karka. Las comidas de los pureres son dos veces al día; muy temprano a las 6 á 7 a.m. préparan caldo de carns de oveja o alpaca, generalmente chalonada, ceba- 
da molida, chuño, traído por trueque de Huancavelica; cancha, mote, el maíz lo obtienen también por cambio, de la selva, Huancayo o de Tupe (parte baja). Se van a pastar llevándose cancha y queso, y a las 5 ó 6 de la tarde que regresan preparan su comida: caldo de cebada: llaman "moron" a la cebada no muy molida, sin pelo, machucada y tostade, esta es coino arroz o granitos y la ulilizan para el caldo o "lagua", El arroz, azúcar y fideos los adguieren en el pueblo, así como papas y sal; al igual que los fósforos, cigarros y alcohol para el chamiscol. En botellas llevan kerosene para sus lámparas. El servicio consiste en mates, cucharas de pelo y iarros de lata.

Las casas 0 chozes en la puna son muy pequeñas, unos 7 pasos normales de largo, por 5 de ancho, la altura es de $1 \mathrm{~m} .40$. Las chozas son de forma cónica, el techo es de paia. La entrada tiene $60 \mathrm{cms}$. de ancho y $1 \mathrm{~m}$. de alto. Dentro de la casa está el fogón. A ambos lados de la puerta se encuentran dos poyos de piedra. Los víveres los guardon dentro de ellas, no existiendo depósitos especiales. El piso es de tierra. También existen pircas al lado de una roca que ellos llaman la cueva y que les sirve de lugar para dormir. Al costado de la choza se encuentra otra destinada al depósito de lana. Las paredes son de piedra, unidas con barro, los palos para el techo son generalmente ds Inaguey. Tcdos tienen por lo menos tres a cuatro perros para el cuidado del ganado. Para dormir tienden mantas en el suelo o sobre los poyos, que son banquitos-de piedra unidos con-barro de un ancho de $50 \mathrm{cms}$, alto de $30 \mathrm{cms}$., largo de 1.60 a $1.80 \mathrm{~m}$. La "cama" consiste en dos o tres frazadas para cubirrse y uno $\mathrm{d}$ dos pellejos de borrega como colchón.

Los corrales para el ganado son de piedra, pircas, de $1 \mathrm{~m}$. a $11 / 2 \mathrm{~m}$. de alto, circulares. Duermen en los corrales cuando la puna está seca, cuando no liueve, de mayo a octubre; pasado este mes y en adelante los sueltan, porque con las lluvias los corrales se atollan, la lana se ensucia y las patas se malogran. Unicamente al ganado menor lo echan a los corrales para evitar el "daño", o sea que los puødan comer los zorros. A los corrales los llevan después de que han comido pasto durante el día, a las 5 ó 6 de la tarde y los sacan a las 7 de la mañana. Además del pasto, al ganado les dan sal en trozos, que colocan junto al pasto, con la finalidad de que engorden.

Los corrales están siempre ubicados en sitios adecuados, en las faldas de los cerros, al lado de una peña, etc., forman muros o pircas, a su lado. Pueden ser también rectangulares. Los corrales no tienen techo. Los animales grandes se separan de los chicos para evitar desór- 
denes y maltrałos. Especialmente en el "empadre", cuando el macho busca a la hembra, hay que cuidarlos mucho porque hay desorden Los animales eníerrnos se juntan en lugar aparte para curarlos. Cuando están afeciados y el ganado comienza a enfermarse y morir es necesario embalsamarlos; el estómago y la sangre los depositan en botellas y el higado se macera en pisco o alcohol en una vasija, y todo eso lo traen a Lima para un examen a fin de obtener el diagnóstico del Ministreio de Agrisultura; generalmente los curan con inyecciones. Las principales enferrnedades son la oftalmia, extranjilosis y septisemia, además las garrapałas y piojos, para los que el bañadero en construcción será el mejor remedio.

Le tiempo en tiempo se realizan rodeos, cuando hay un deslinde de jurisdicción con los pueblos vecinos o cuando deben recorrer la comunidad por orden del Ministerio o la Prefectura. Todos los ciudadanos están obligados a concurrir, el que no va, paga su multa $\circ$ "fa!la" que es a beneficio de la Comunidad, ésta puede ser de dos a diez soles diarios, según el acuerdo comunal. El rodeo dura generalmente de 8 a 10 días. Deben participar también las viudas. El último rodeo que se realizó fué en 1938 para el deslinde con las comunidades de Painpas y Cacra y con Acobambilla (Huancavelica); la Hacienda Tucle estaba invadiendo los terrenos pastales. A.compañaron el rodeo o "recorrido" una pareja de guardias civiles. En la fecha indicada fué el ingeniero Padilla para levantar el plaño catastral de la comunidad. .Cada uno lleva sus alimentos para ellosey pararalimentar a los guardias e ingenieros. Unos van adelantados a fin de ir preparando la comida, en las estancias.

Muchos de los que arriendan los pastos comunales no tienen tiempo suficiente para dedicarse únicamente a la puna, puesto que son también agricultores o son llamados a desempeñar un cargo en el pueblo. Entorices tienen que subarrendar sus paraderos a otros tupinos que tienen tiempo y que son sus vecinos 0 familiares, 0 a pastores de otras jurisdicciones, como de Pampas, Huantán o Cacra. Para esto tienen tres formas de contratos: el subarriendo, el subarriendo en compañía y el "pagado".

El segundo es el más usado. Cuando dan "en compañía", todo lo hacen por partes iguales. Medio año se mantiene el pastor y medio año lo mantiene, el dueño. Las pérdidas intencionales son pagadas por el pastor y las producidas por enfermedades o accidentes son pérdidas del dueño. Los víveres se los llevan o los pastores vienen por 
ellos a Tupe, según el contrato, que es anual. Las crías se reparten a medias.

Cuando son arrendadas (subarriendo), hacen el contrato por un año y pagan una suma fija mensual, S! 30.00 generalmente. Los puneros están en la obligación de cuidar el ganado junto con el suyo. 'Les proporcionan pastos para ambos ganados y además comida: un saco de papas, uno de maíz, uno de cebada, 3 arrobas de azúcar, 2 arrobas de sal y les dan 3 borregas al año. Ellos se proveen de leña. Los productos del ganado son para el dueño; además cada mes les dan un vellón de lana para que hilen sus vestidos. El contrato se hace por escrito ante el Juez de Paz.

La tercera forma de contrato, también anual, es el "pagado". Les pagan un sueldo por cada ciento de cabezas que cuiden, 8 á 10 soles mensuales por cadá ciento, les dan comida y pasio. Cada mes deben darles víveres, y la manutención es por todo el año.

En estas tres formas de contrato los dueños van a vigilar a los pastores cada 15 á 20 días, ahí les llevan comida y paga.

En el arriendo (subarriendo) hay otra variante, según contrato, hacen arreglos especiales para las crías. El pasior puede tomar en arriendo las ovejas y se queda con las crías, pero debe buscar el pasto.. El dıeño no se preocupa por el pasto.

Las dificultades de estos subarriendos cada día son mayores y por eso ellos prefieren sacrificarse afendiendo personalmente el negocio.

Los pastores usañ onuch lel sultato de estrionina, como veneno contra los zorros, en trampas envuelven la estricnina con carne y la dejan en el camino del zorro, después que éste ha comido una uveja el día anterior. También usan slandestinamente escopetas y todos tienen sus hondas.

Los puneros para la adquisición de sus víveres utilizan de preferencia el trueque y ello lo hacen más con los de afuera que con el pueblo. Durante los meses de mayo, junio y julio con 20 a 30 llamas, van a los alrededores de Huancayo a buscar las "sementeras" de maíz y cebadá, especialmente por el lado de Chongos Bajos. En agosto hacen viajes' especiales a Lampa, en la montaña, a 3 días de camino después de Huancayo, para la cosecha de maíz. Todos estos productos son traídos por cambic, no por dinero. En noviembre van al pueblo de Tana a traer maíz. y durante los meses de febrero a abril bajan por todas las quebradas a la costa o zona yunga, a Zúñiga, Pacarán y Lunahuaná, para obtener frutas, especialmente uvas y licores. A Huancavelica van por chuño. 
Durante los meses de mayo a octubre, especialmente, y siempre que tienen tiempo, se dedican a la manufactura de los productos que les servirán para el trueque. Hacen vestidos, mantas, ponchos, cordellates para partalones, bayetas, jergas, sogas, huaracas, medias, chompas, etc. Las mantas que tejen son de tres clases: chicas, regulares y grandes, confeccionadas con lana de alpaca y borrega y son tejidas de preferencia por hombres en telares de mano. I.as sogas las hacen de lana de alpaca, de 6 á 7 brazadas; llaman una brazada a la distancia que hay desde la punta del dedo medio de la mano izquierda, con el brazo extendido, al hombro derecho, las hacen con 5 torceduras y las utilizan para cargar las llamas. Estas sogas son muy apreciadas. A las llamas no les colocan aparejos, sino que encima del lomo les ponen alforjas de lana de alpaca o borrega hechas por ellos mismos o sino, son "alforjas costales", en las cuales colocan la carga y cuando ésta está encima del animál cosen el costado abierto y lo tercian, o sea que se amarra ya acomodada la carga, es el remache, que es diferente al usado al cargar las "caballerías" Ias sogas pasan por el pecho y la parte baja del lomo.

Los ponchos los hacen de dos tamaños: chicos y grandes, y son de lana de oveja y de color nogal. Las guaracas y hondas de 1 á 2 brazadas de lana de alpaca. Las bayetas las hacen en telares a mano y sirven para el centro 0 pollera de las mujeres. También hacen medias largas, la planta de lána de oveja y la parte alta de lana de alpaca. Las chompas "de lana de Covejall con mangas y sin ellas, con punto trenza o a canelones. Tejen frazadas de lana de alpaca u oveja. Hacen costales especiales llamados "topos" que les sirven de medida para su intercambio, que consisten en mantas cosidas en forma de costal. Los hay de diversos tamaños. Esta medida, según acuerdo con los negociantes, la llenan con mazorcas de maíz o maíz desgranado, a cambio de sus productos. Un vellón de lana de oveja es igual a un costalillo o "topo" lleno de mazorcas de maíz. Para cada cambio usan un tipo de "topo" que es llenado según lo que se da. El cordellate es un tejido de lana de oveja, cada pieza es de 15 á $20 \mathrm{~m}$. de largo. Lo cortan por metros y es usado para pantalones.

Además del "topo" que usan para sus intercambios, acostumbran hacer trueques usando como medida de cambio "matecitos" de lagenaria. Estos matecitos son de propiedad de los negociantes y cambian por ej. una guaraca por uno lleno de arvejas, habas o trigo.

Además de los productos que elios confeccionan venden las ovejas o alpacas, pero ahora su venta es mínima. 
Lo que raćs venden son los vellones de lana tanto de alpaca, co. mo de oveja, la carne chalonada y tejidos. Ips llevan a la feria de Huancayo y a la montaña para su venta o trueque. Para eslo usan como cargueros a las llamas y las alpacas cuando son "capones". A la selva únicamente llevan llamas porque son más resistentes, se pasan sin comer hesta una semana. De la selva traen especialmente maiz, a veces gallinas que las consiguen a 50 ctvs. cada una, los pollitos a 30 ctvs. Tarzbién cañas que usan para torcer las sogas, cada caña tiene 40 á $50 \mathrm{cms}$. de nudo a nudo y son de varios metros. Asimismo yerbas como la "sipita" que sirve para curar a las llamas de la gusanera, esios animales acaban el pulmóa y el hígado de las llamas rápidamente. La "sinita" se muele bien y se hierve mezclándola con un poco de sal de comer. La poción, una botella llena, que es bien amarga la dan a cada llama en caso de enfermedad. También traen "cainairos", una corteza de árbol que usan para endulzar la coca que "chacchan". El "camairo" lo mascan y arrojan la soropa, enseguida llevan una a una las hojas de coca para chaccar"; con el gusto dulce que deja la planta, la coca se hace más agradable.

La coca, de la que hacen bastante uso en esta zona frígida, la compran en Huancayo, por dinero a los negociantes que la traen de Huanta. Cuzco y Huánuco. La mejor coca es la de Huanta. Se compra por libras y arrobas. La libra vale $S \mid 3.50$, una libra completa S!. 4.00 y la arroba de S|. 70 á 80, según la calidad. La mezclan con cal, ésta se extrae de diferentes lifgareslagl ae puna pen/ divessos cerros; hay tres tipos de cal. El que más usan es el "añasmate". El otro tipo es el "kalikante", més fuerte, querna la boca y es pozo utilizado. Lo usan para pelar mote y maíz. El tercer tipo es e! "bakakale" que es muy fuerte, de poco uso para chacchar.

De Huancayo en cada uno de sus viajes compran lo suficiente para sus necesidades, esto lo hacen con dinero: sal, fideos, arroz, azúcar; el arroz es muy poco usado porque con la cebada tienen un gran sustituto. También cor pran arilinas o tintes.

Prefieren hace: sus compras por el lado de Huancayo porque ade. más de haber variedad es más económico que hacerlo en Tupe 0 ir a Pacarán, frecuentemente, o Lunahuaná que es muy lejos. A Catahuasi bajan constantemente llevando carnes, lanas y tejidos para cambiarlos por yucas.

La cordillera que pasa por la laguna Warmicocha se Jlama $A k^{\prime}$ chikocha. Es larga, alta y blanca. Hay una leyenda sobre slla. Antiguamente existió una disputa entre esta cordillera y la de Uturunko que 
está situada al lado de la selva, son dos cordilleras de gran "potencia", majestuosas. De Huancavelica va la primera en dirección a Yauyos, al lugar llamado Longcte. Ak'chikocha tiene la forma de un pico alto, como lo torre de una íglesia y dicen que tenía una cruz de oro en su cuello. Hasta ahora, ellos manifiestan distinguir la huella. Ambas cordilleras pelearon por la cruz de oro, discutieron largamente y para acabar con el pleito, decidieron que el que se llevara la cruz, o corona, según otros, no gozaría de las vicuñas. Pero Uturunco quería a toda costa la cruz y las vicuñas y un día se la quitó a Ak'chicocha. Desde esa fecha una quedó con la cruz y otra con las vicuñas. Por eso dicen los de la puna, pasando esta Cordillera de Ak'chikocha no hay ahora vicuñas, de Huancayo a la selva no existen, debido a este suceso. Creen que actualmente la cruz de oro está en el cerro de Uturunko. Esto explicaría la abundancia de vicuñas en la puna de Tupe.

GANADERIA EN LA PARTE MEDIA (QUEBRADAS).- A diferencia de la puna, la ganadería en Tupe y las quebradas de la zona media del área del "kauke", tiene una importancia secundaria. Los animales son muy apreciados tanto por los productos que de ellos aprovechan como por constituir su capital. Para una fiesta, para un cargo, un pleito, más que empeñar shacras, el ganado les proporciona el dinero suficiente a fin de adquirir lo necesario para afrontar sus diferentes necesidades. El ganado no absorbe como en la puna todo su tiempo y dedicación, porque ante tcdo soñ agricultoresinelli Converso"

Ganado vacuno.- Constituye la principal riqueza de los tupinos, tanto por su valor como por los productos que de él abtienen. La posesión de mayor cantidad de vacunos es señal de riqueza y prestigio. A diferencia de lo que sucede con los otros animales hay familias que no lo poseen. Cada familia tiene de 2 á 40 vacunos, como máximo. Estos animales proporcionan la leche, con la cual hacen su queso. Una familia no puede dejar de comer queso un día, lo necesitan, están acostumbrados a su uso diario, es el complemento de su cancha, de sus papas. Además su calzado provienle del pellejo o cuero de vaca. Estas dos utilidades del animal hacen muy estimados y valorados a los vacunos. De ahí el esmero con que los cuidan. Pocos son los que se dedican al negocio de vacunos.

Algunas personas poseen sementales Holstein de segunda y tercera sangre. No los compran de primera sangre, porque son muy caros y necesitan mucho cuidado, pasto todo el año, además el terreno escabroso no permite andar bien a esta clase de animales. Las de so- 
gunda y tercera sangre necesitan menos cuidados y pastos, pueden fácilmente soportar los malos tiempos junto con las vacas corrientes. Estos sementales, los machos, son prestados o alquilados en las "echadas al cerco" a diferentes personas para que crucen' sus ganados.

El cuidado de los vacunos está a cargo generalmente de las mujeres y pocos son los hombres que lo hacen, aunque los muchachos de 14 ó más años también los cuidan. Diariamente los sacan de su corral, que es el común para las ovejas y cabras, ubicado en las afueras del pueblo. No hacen los corrales muy lejos del pueblo porque los pumas o zorros los pueden atacar y en una noche devorarlos, cerca del pueblo no sucede esto. Cuando hay alguna fiesta son llevados un poco más lejos del pueblo, a sus chacras, para evitar el tener que llevarlos y traerlos diariamente. En ellas hay corrales que están constituídos por dos 0 tres andenes pircados, ahí bajo el cuidado de un pastor que duerme en una choza o "ramatúa" pasan la noche. A las vacas lecheras siampre las separan de sus crías y después de "lecharlas" o sea ordeñarlas las juntan. En todas las andenerías de la quebrada hay por lo menos dos o tres corrales de esta clase, tanto en la parte alta como en la parte ba ja. Es' ein estos corrales, que a veces distan un día de camino del pueblo, donde realizan la herranza de su ganado. Los principales corrales al lado del pueblo son los de Vil'akanka, a la vera del camino de Aiza a Tupe. Son dos andenes arriba y dos abajo, pertenecen a dos dueños. Encima del cementerio, al iniciarse el lugar llamado Huancracha, hay varios corrales. También un poco abajoSdel cementerio y antes de que comiencenglas primeraslicasas hay stros corrales. En Mil'po, a la salida del pueblo, por el camino a Colca, antes del río Cuchapaya, existe otro corral. T'odos son andenerías, dos o tres andenes pircados. Cada uno de los andenes usados como corral contienen entre 10 á 20 vacunos. El más grande es el corral de "Shusho" que era €.l antiguo carnoo deportivo, al lado Este, en las faldas del cerro Pupre. Esta pampa es de la Comunidad, y está distribuída en diversas zonas, ahí puede entrar mayor cantidad de ganado.

Al ganado vacuno lo aprovechan en su came, leche, cuero y cornamenta. De la carne hacen chalona, la leche para queso, el cuero: para zapatos ("shukúy"), "reatas" o sogas; las astas para cornetas y depósitos de curajo. Al cuero de los animales le echan sal para secarlo a fin de que no se endurezca.

La carne de los vacunos se aprovecha únicamente cuando uno de ellos sufre un accidente, un despeñe o un descaderamiento, o cuando 
se hinchan por comer mucria alłalfa verde. Nunca se dá el caso de que alguna familia sacrifique una de sus vacas o terneras.

Inmediatamente que se produce un accidente la genie acude donde el dueño a adquirir un poco de carne fresca muy apreciada; pero como ahora los dueños cobran caro, po: un kilo, entre dos o tres soles, prefieren no hacerlo, los que han estado en la costa y los accinc dax: son los únicos que la compran. Lo que no se vende o aprovecha, lo chalonan inmediatamente, para una res basta una arroba de sal. Cuando muere una res el dueño y algún familiar o amigo acude al lugar y la despellejan con mucho cuidado tratando de sacar el cuero intacto. Una vez despellejada, corta las piernas y brazos, la cabeza y el cuerpo lo dividen en dos partes, los acomodan en trapos blancos y lo llevan a su casa, si hay mujeres ellas cargan en sus quipes. Una vez en la casa, con cuchillos y machete se corta en trozos, esta operación la hace el dueño o algún amigo o vecino, el cual recibe en recompensa un buen pedazo de carne. Cortan la carne en tiras delgadas, para luego chalonarlas; los huesos los usan para caldo; la sangre no la utilizan, generalmente se pierde en el campo; Y las vísceras, riñones e hígado, las comen hervidas y fritas.

Una buena vaca lechera se vende entre 600 y 700 soles en la costa, Cañete. De segunda clase entre 300 a 400 soles. Hay algunas personas que se dedican al hegocio de vacas, especialmente en Aiza. Reúnen de varios dueños dos o tres vacas y con las ovejas las llevan a los camales de la zona yunga TEn Lunahuaná, en el camal les pagan 30 soles la arroha.JoEnel Pulcáldíali existererun." regisiro de los que se dedican a la ganadería de acuerdo al Decreto Supremo de 4 de noviembre de 1921, para que puedan ejercer libremente la industria ganadera dentro y fuera de la jurisdicción. Para esta licencia deben pagar según su categoría entre 50 á 10 soles. Pagan 50 soles aquellos que venden 200 o más reses, según ley, pero en el pueblo nadie llega a pagsr esa sirria, pagan entre 5 a 20 soles. Cada vez que van a lievar ganado en venta sacan un perniso de la Alcaldía, es otra licencia que cuesta entro 5 a 10 soles, debidamente sellada e indicando la cantidad del ganado que llevan, les sirve de pase en todo el camino, porque sino la Guardia Civil en' Catahuasi los detiene. Junto con la licencia deben llevar su patente de negociante, que también es otorgada por la Municipalidad, desde 1948, y la carta venta si los compraron. Cuando son suyos los animales deben tener carta del gobernador. Este dinero de licencias y de patentes, es una entrada para la Municipali- 
dad que se usa en los pequeños gastos de útiles de escritori, y representación del Alcalde.

La leche es usada casi exclusivamente para hacer queso, poco se aprovecha en el consumo diario. La leche de vaca blanca les hace daño, les produce dolor de cabeza y no la toman, dicen que es muy "fresca", solamente toman la de vaca negra.

Después de ser "lechadas" o sea ordeñadas diariamente las vacas, cuando el sol llega al corral, porque antes no lo hacen, cuelan la leche en un tocuyo, de un balde a otro e inmediatamente le echan la cuajada o cuajo que puede ser comprado o confeccionado por ellos. El comprado es el cuajo extranjero que venden en las boticas y que traen de Cañete o Lima, se vende en Tupe en tubitos de 25 pastillas a S|. 15.00 y cada uno a S| 1.00. Para un balde de leche, unos 4 ó 5 litros, le echan menos de un cuarto de pastilla. Una pastilla dura a veces una semana. Ell cuajo que preparan lo hacen de la panza (cuajar) de una borreguita o uri cakrito chico; la panza se limpia, luego se llena con leche de vaca, bastante sal y limón, y se cuela a fin de que seque. Después de meses, cuando ya está completamente seca y bien dura, recién puede usarse. Permanece cclgada en la puerta de la cucina o de la casa y cuando la necesitan cortan un trozo chico, panza y todo, y lo disuelven en un jarrito con suero o bien con un poso ae agua tibia, y disuelto lo echan a la leche. Si es buemo, a los 10 ó 15 minutos la corta, sino demora un poco más. Mientras está por cortarse, la persona que hace el queso, que generalmente es mujer, se laval las manos. Esta operación la hacen siempre en losccorrảes yı mientras, las vacas están pastando. Introduce las dos manos en el balde, lo mueven con mucho cuidado, luego de asentado, botan el suero a un recipiente para los perros, también lo usan como mazamorra: hirviendo el suero, maíz molido blanco o harina de trigo, con un poco de canela y azúcar. La leche cortada queda asentada en el fondo del balde y con las manos es asida y llevada a moldes especiales de "champakara" llamados "estera" que son tejidos por ellos y tienen la forma rectangular de unos 10 á $20 \mathrm{cms}$. de alto por 70 á $90 \mathrm{cms}$. de largo que colocan sobre un mate 0 un plato, lo enrollan y amarran, en su interior, introducen la leche cortada que es el queso, lo aprietan bien y le echan sal. Para que se ponga bastante duro le echan mucha sal. Para que sea mantecoso poca sal. Este es el mejor, usado para caldos y chupes. Todos los días las mujeres o muchachas hacen el queso que es el alimento principal. Hacen también quesillos que son quesos frescos que no se orean. De un balde lleno de leche, unos 4 ó 5 litros 
sale un queso de una, dos y dos y media libras. La libra de queso la venden a 2.0. soles. Todas las casas tienen lugares especiales para guardar el queso, en unos aparatos de carizos colgados del techo llamados "barbacos".

A las vacas generalmenle, cada dueño les dän nombre, desde que nacen, lo que no sucede con los otros animales. Las llaman Yolandina, Rosairina, Holandina, Carbonera, Peruanita, Esperanza, Napolitana, Australiana, Medolina, etc.

Los principales peligros para los vacunos son los desbarrancamientos y la hinchazón debido a la alfalfa. El primer peligro se debe a lo accidentado de la quebrada y el segundo a que en ciertas épocas del año, enero, frecuentemente, el pasto no bien maduro al ser comido en abundancia por los animales les infla la barriga, el aire se deposita en la panza y es tan fuerte la presión que revientan.

Peligros consecuentes de la topografía del suelo, son las luxaciones, descaderamientos, fracturas, etc. Para esto entablillan las patas de los animales y les dan el tratamiento descrito más adelante para las ovejas. Cuando se descadera una vasa, tratan de venderla o sino la matan al momento, porque dicen que cuando pare se muere la vaca y su cría. Se ha dado el caso de que pára salvar la crîa han abierto el vientre de la vaca.

La principal enfermedad de los vacunos es el carbunolo, para combatirla los vacunan o les aplican inyecciones. Para ello los cogen por los cuernos y la nariz. Tres personas realizan esta operación, limpian la parte de la pierna dofrae vancanaplicarolatacuna o inyección, con alcohol, antes y después de aplicarla.

Cuando una vaca pare se le presta mucha atención, si se le sale la "madre" (el útero) le aplican alcohol al ano o sino le colocan un emplasto de marko (artamisa). Las' mujeres cuidan a sus vacas, permaneciendo a su lado listas a ayudarlas y apenas paren las llevan al pueblo, si están cerca, y allí les llevan pastos; a la cría, apenas nane le limpian el cuerpo con hierbas o bien con la mano y la ayudan a pararse, luego la hacen mamar. Desde que la vaca está con síntomas de parir hacen apuestas entre los familiares o vecinos tratando de adivinar el sexo de la cría y cuando pare hay fiesta, contratan una orquesta y bailan "vakataki". El que pierde la apuesta paga generalmente una botella de menta, pisco o chamiscol. La placenta de la vaca cae sola, no se le ayuda en ningún caso. Apenas arroja la placenta la ordeñan y la leche que sale es llamada "corta", amarilla y espesa. Esta "coria" se prepara antes de ser hervida, primero con un poco de suero, 
para que no sea tan espesa, luego la hacen hervis con cansla, anís, y azúcar y se toma en platos con cancha, es uno de los alimentos más apreciados y agradables para los tupinos. El nacimiento de un ternero es señal de alegría y buena suerte, si es vaza es mejòr, si son mellizos tanto mejor. Es más riqueza.

También el ganado es afectado con fiebre aftosa y se le cura con inyecciones. Otra enfermedad es la "tocazón" o sea cuando el librillo se seca debido a la alfalfa muy madura y a que no ha tomado agua. Se vuelven medio locas. Las curan con suero, sal y la yema de la panca de la tuna blanca.

Llaman "jorras" a todo animal que no da leche y estos cuando hay ezcazes da pastos son los más sarrificados y los menos atendidos. Pueden ser toros, becerros, vaquillones o vacas ya secas que no tienen cría. Cuando se seca la leche de una vaca que ha parido, debido a que un toro la ha "pisado" se convierte en "jorra", en realidad la verdadera acepción del vocablo. Cuando hay alguna fiesta o actividad como la siemibra, que les va a ocupar mucho tiempo, especialmante en los meses de febrero a junio, llevan las jorras a las alturas para que coman los pastos naturales, que en esa época están bastantes buenos, la víspera hacen una fiesta, primeramente, mandan cantar un responso a las ánimas, y con la familia, reunida se toma y baila "vakataki" durante toda la noche. Al día siguiente enfiloran las jorras. Enflorar es adornarlas con flores naturales. La persona 0 personas que llevan las jorras, especia!mente mujeres, aunque los hombres a veces lo hacen, son así mismo enfloradas y pintadas la cara conmachica; llevan una boteilita chica, de Thimolina,glena de lalcoholoun atadito de flores y un jarro para la "uksa". La uksa consiste en agua con máchica, o maíz molido blanco y un poco de flores. Todas las personas que pasan por la casa en el momento de ser llevadas las jorras son pintadas con máchica en la cara y convidadas con "chamiscol". La pastora o pastor lleva su fiambre para el viaje: cancha y queso. Lbs familiares y amigos los acompañan hasta la salida del pueblo. El viaje dura un día. Llevan a los animales haciéndoles dar un gran rodeo, antes de llegar al sitio indicado, a fin de que se desorienten y no regresen fácilmente. En el camino se detienen en todos los puquiales y toman primero agua de ellos y luego van dejando flores. En muchos puquiales hay claveles marchitos que indicar el paso de otros pastores. Al llegar al lugar donde van a ser dejados los animales, lugar de bastantes pastos naturales, buscan un puquial, colocan el resto de las flores acomodándolas cuidadosamente donde brota el agua, echan el pisco, sacan agua en el 
jarto y preparan la uksa, la derraman sobre la tierra esparciéndola en forma circular y dicen: "Santa Tierra cuida de los animales, no les hagas caor, ni regresar". Este es el cumplimiento que dan a la tiersa para oue cuide y proteja a los animales. La misma ceremonia se repite en óro sitio vecino. Al día siguiente un miembro de la familia los va a vigiiar y luego lo hacen ceda cuairo o cinco días.

La "vaquería" es una de sus fiestas ganaderas. Tiene además de este significado, un móvil vital, cual es alimentar a sus animales. Por esie motivo no lo mencionamos en el capítulo de fiestas ganaderas. Se rexliza en marzo y abrii, tanto en la parte alta (puna) como en la parta ra dia (quebrádas); en la parie alta cuando pasan las lluvias y el pasto está crecido. Llevan los animalss a los pastos naturales en diversos sitics pira que los aprovecinen y para eso se juntan varias tamitias. Para llevar los animales hacen una gran fiesta, en la víspera los dueños contratan una orquesta y se baila "vakataki" o "uakaira", ioda la nccine. I.a orcuesta estí compuesta por dos violines, arpa y una tinya, que siempre es locada por una mujer. Antes de iniciar el baile se contrata a uno de los invitados y le pagan cincuenta centavos o un sol, para hacer un "responso" a fin de que le vaya bien a los animalss. Ail día siguiente, se preparan para el viaje muy de madruga$\mathrm{da}$, todos bien "enflorados", llevan la uksa, flores, licores, frutas, etc. Todas las cosas que llevan son para pagar a la terra, porque dicen que ella está viva y hay gue hecerie una cirenda o fin de que cuide a los animales.

Cuando son llevados despanimales hacia la parte frígida van a los pastos naturales y cuando los llevan abajo, van a los cercos que son de propiedad particular. En este caso está estrechamente vinculada a la "echada al cerco". "Echar al cerco" es llevar los animales a un cerco, del cual ellos son dueños y la vaquería es la permanencia en el cerco cuidando a sus animales.

Durante la permanencia en la vaquería se realiza una serie de actividades, todas acompañadas de música y bailes. En essa época el aruce de los animales es más propicio. Debido a la abundancia de pastos y sobre todo a que ellos son pastos naturales, el queso que preparan es el más rico que se come durante toda el año. Mientras dura la permanencia de las pastoras en la vaquería, son visitadas por los muchachos, especialmente los ívenes que las enamoran. Los chicos que acompañan a las familias en la vaquería, durante las noches jue. gan tratando de imitar a las sociedades religiosas, uno ha de ser Presidente, hacen sus acuerdos, su "kermesse" (remate) todo ello en un 
lado de la chacra al cual le dan el nombre de un "calfón"; simulan una procesión y entonan canciones. Mientras tanto las madres preparan la comida y después de ella bailan. Cuando una persona visita la vaquería le invitan un mate grande, lleno de cuajada con cancha, obligándole a acakarlo y luego hacen lo mismo las otras familias que están en la vaquería. No se puede despreciar a nadie. También hacen quesitos llamados San Lucas, que regalan a los visitantes. Para cocinar sus alimentos las vaqueras escogen la mejor leña y siempre preparan una infusion de huamanripa. Las familias van turnándose en el cuidado de sus animales y generalmente son las hijas las que los cuidan.

El queso que preparan tiene tres sabores: 1) la "cuchupa", que es ei borde del molde del queso, tiene poca sal, lo hacen helar durante toda la noche, junto con el molde del queso y lo comen al día siguiente $\circ$ los pasieriores. Es generalmenta hecho en abundancia para iser invitado a los amigos. 2) la "masara", que tiene otro sabor y que no es sino el residuo del queso, lo que se desmorona y no llega a ponerse al molde. 3) el queso en molde, que es bastante grande hecho para la venta en la costa. También hacen "quesillos" en mates chicos, a los cuales les echan poca sal y no los hacen orear; son para el consumo diario.

Un día en la vaquería transcurre así: Muy temprano las mujeres preparan el desayuno, éste consiste en leche con canela, cancha, mote, queso, cuajada y un chupe a base de papa y carne seca. Después del desayuno, todas las vaqueras comienzán a ordeñar las vacas en mates, latas o baldes. Cuelan la leche, preparan el cuajo en un jarrito, lo echan a la leche y Ra dejan cortar. "Luego Mlevan" las vacas a pastear. Regresan a medio día. y preparan el queso; haciéndolo en moldes sobre una piedra y con grandes bordes, (cuchupa). Otros se dedican a buscar leña en el monte. Algunos regresan al pueblo llevando leña. Los animales pastean solos. Al ponerse el sol encienden el fuego para preparar la comida de la tarde. Especialmente preparan "requesón" o sea el suero hervido. En la noche se alumbran con las hogueras, cada vaquera tiene su fogón. Los utensilios de comida son ollas de barro, mates y cucharas de palo. Mientras comen un violín toca un "vakataki" y se baila y conversa durante unas horas. Para dormir preparan pellejos de oveja y usan de cobertores, mantas (kátra). La choza donde duermen consiste en una pirca rectangular de piedra, de unos 80 centímetros de alto, cuyas tres cuartas parte están cubiertas por una ramada de arbuștos secos muy ralos. Al lado están los fogones, al fondo hay una piedra plana empotrada que sirve de alacena y dos bata- 
nes a su cosiado. Alrededor de la choza hay yarios corrales donde duermen las vacas y los becerros por separado.

Ovejunos.- El garado ovejuno es el más numeroso. Las ovejús y los caineros, juríándolos en número de 40 ó 50 los llevan generalmente a Cañete y ahí los venden, con lo cual adquieren ropas, herramientas, remedios y alimentos. También acostumbran venderlos anles de pasar un "cargo" en alguna fiesta, principalmente para las he. rranzas.

Ninguna familia deja de tener ovejunos y su cantidad varía entro 10, los más pobres y 50 á 60 los más acomodados. No hay sementales de pura sangre, pero sí existen carneros de tercera sangre de merinos. Llaman de tercera sangre a los nietos de un semental fino.

Todas las familias participan del cuidado de las ovejas y diaria mente las llevan a "pastear" junto con los vacunos y caprinos. Generalmente los niños deste los $\varepsilon$ años son los envargados de cuidarlos durante todo el día. Las mujeres ambién lo hacen, y los hombres únicamente cuando los niños están en la escuela y las mujeres ocupadas en la "kushpa", "rekushpa" o siembra. Cuando hay abundancia de pastos los llevan a las alturas de la quebrada para que engorden, $y$ cuando éstos faltan a los alfalfares. De octubre a enero hay escasezt de pastos $y$ alfalfares y es la época en que sufren mucho. Esta escasez es general en toda la quebrada y puna, tanto para los animéles como para los moradores debido a que se les agotan las reservas.

$E_{n}$ sl pueblo cada duper o tiene ludares especiales, algunos son corrales, donde e! ganado pasa la noche. Gfneralmente, están en les en-

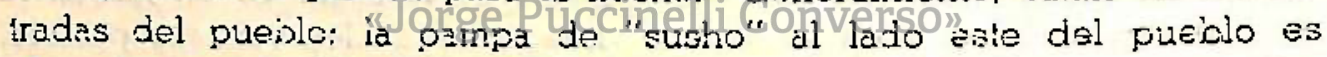
el mejor corral. No existen corrales especiales. Los abrigos o corrales son naturales, no tienen ninguna pirca y además son generales para los vacunos, ovejunos y caprinos. nada.

El carnero con "cuernos" se llama Inga y es el que dirige la ma-

Los ovejunos se aprovechan en su carne y lana. Cada carnero. se vende en 25 a 30 soles en el pueblo; en Cañete de 35 a 40 . La carne de los carneros se prefiere a la de las borregas por ser más dulce y agradable. Para cada fiesta o ceremonia comunal, las familias matan uno o dos de ellos. Por ejemplo para la fiesta de San Bartolomé y la Candelaria los mayordomos y mayoralas mataron cada uno un carnern y ura cabra. También cuando una familia quiere comer cârne fresca en cualquier época mata un carnero, para ello escogen el más gordo que se conoce por el "rabo" o cola; si está duro es flaco, si es- 
tá blando es gordo. También se conoce por el pecho y los ojos. Una vez escogido el carnero, en la puerta de la casa o al lado de la cocina, preparan una olla para recibir la sangre, buscan un cuchillo el cual se afila en una piedra especial; los hombres son los que matan a las borregas, se lavan las manos y piden otra olla con agua limpia y unos secadores. Amarran las patas del animal y en' el suelo lo voltean, otpa persona ayuda en esta operación, puede ser un chico o una mujer $u$ otro adulto, el matador coge con una mano el hocico del carnero y con la otra el cuchillo, el corte lo dá en el cuello, el animal apenas si se queja, otra persona rápidamente coloca la olla al cuello del animal para recoger la sangre. Luego en una de las patas traseras y en la partó superior hacen un corte peग̃ueño por el cual inflan fuertemente a tin de que el pellejo se despegue de la carne. Esto tiene que hacerse irmediatamente, así se facilita la obaración de despellejar. Después de inflado, el tercer corte se da en la panza y pecho haciéndolo con mucho cuidado y esmero para no cortar la carne y pcder sacar el pellejo entero; con la marn y pur̃o separan el pellejo de la carne tirándolo fuertemente. La habilidad del desollador se conoze cuando saca el pellejo sin dañarlo. Terminado esto, el animal queda limpio y el peilejo en el suelo, encima del cual colocan al animal. Luego cortan el vientre y extraen las vísceras. El "capacho" o cuero de los testes se da a los chicos páral que lo cusen] como pelota (makuru). La vejiga (pusputa) también sirye de juguete a los niños. Las vísceras se depositan en un balde y son lavadas por mujeres para "preparar el mondongo. Una vez extraidas todas ellas se lava el interior con agua fría y al animal lo ruelgan con una soga de "diampakara" en la parte alta de la cocina, amarrado de las dos patas traseras para que se oree, abriendo la abertura de la panza con palos delgados o carrizos. Para cocinarlo to cortan en pedazos, las piernas son las más codiciadas y para el caldo la cabeza; en caso de que no se utilice todo el animal, al día siguiente lo chalonan, para lo cual usan sal. La sangre la comen preparándola en saltado; el corazón en caldo, no se fríe nunca; el hígado y riñones cocidos se frien en cerueños trozos. El resto de las vísceras las comen haciéndolas hervir, $y$ en trozos pequeños son fritas con papas, es el mondonguito o caucau. Los huesos sirven para caldo, lo mismo que los patas. No se dehe matar una oveja cuando uno ha venido de la costa porque le da paludismo, tampoco debe matarlo cuando la mujer esti on cinta, porqua el arimal sufre al ser degollado.

El pellejo es secado al sol y después de dos o tres días, bien lavado sirve para lo que vellos llaman cama, o sea de colchón para dor- 
mir. Los peileios son muy epreciados, los venden a 3 ó 5 soles adł uno, siendo la venta excepcional, porque los necesitan siempre.

En el pueblo trasquilan las ovejas en marzo y la lana la venden por vellones o libras, cada vellón vale de tres a cinco soles.

Usan las paias para remedio; haciéndolas hervir con linaza, aceite rosado, sal, almendra y azúcar, bien colado sirve en enemas, y para combatir la feebre. A veces le echan un pedazo de jabón.

La lana de oveía la usan para tejidos: la lavan primero; luego la escarmenan, "pushkă" (hilan) y ovillan. La lana debe ser lavada eon agua tibia para que salga toda la suciedad. Esto lo hacen las mujeres. La lana también se lava con el jugo de las hojas machucadas del maguey. Sirve para la urdimbre de las mantas, tanto de las corrientes manta negra (katra) y de las mantas coloradas de fiesta (milakatra). Tamioién se usa pra los ponchos en la urdimbre y en la tréma. Para esto tiñen la lana blanca con corteza de nogál. La lana es teñida en diferentes colores con anilinas o tintes que se compran generalmente en Huancayo o a los puneros que vienen al pueblo. Para las jercas la usan tanto para la urdimbre como para la trama. También sirve para las guaracas.

El hilado puede ser de dos clases: de una hebra y torcido. El torcido es de dos hejras, es más durable y mejor. De un vellón de oveja sale un "bolón I de lanè.e Para la urdimbres de una manta entra un vellćn de lana $\rho$ sea 10 á li enzas aproximadamente.

Usan los pellejos como colchones para dormir y para caronas o aparejos en los cargueros (burro o mulas). La "Uaskara", cuero de oveja, para que no se encoja ni se arrugue, lo hacen secar al sol, templado por seis o siele carrizos, puede también usarse palos delgados. Estos carrizos no se amarran, se sujetan a las puntas del pellejo para lo cual la dan un pequeño corte. Uno va de la cabeza a la cola, otro de las dos patas iraseras y las delanteras.

Entre las principales enfermedades de las ovejas están la sarna, la piciera; y las luxaciones, su principal accidente; culando se "desconcierta" ura pata, la entablillan con palos de maguey, especialmente la corteza porque es más fácil el "pegue", y la venden con una faja vieja hasta que sane. Si es un poco grave le aplican aceite de lagarto. Cuando hay mucha humedad se descascaran las pezuñas las que curan con orines humanos calientes, mezclado son "cashi"-suero (el suero salado sobrarte del queso) y con agua fría. La sama se cura con sebo o gordo de vaca o de alpaca calionte, gues se aplica a la herida. Ciuando. 
tienen piojera las trasquilan y las bañan con agua de ceniza hervida o tarnbién les aplican D.D.T. o sulíato de cobre.

En el mes de mayo paren más las borregas. Nunca se atiende cuando pare una borrega. Tienen "mal parto" cuando los "mochos" (machos) las pisan estando preñadas, período que dura cinco meses.

Las herranzas de los ovejunos se hace por separado de la de los vacunos. Comienzan en junio y se efectúan hasta agosto. Especiaimente se herranzan el día de San Santiago, 25 de julio. La herranza está rodesda de una crran ceremonia al igual que la herranza de vacas. Se baila, la música es el valiataki con tono especial para las borregas. En el corte de las oreias les colocan también cintas, pero no se les marca ni se toma su sangre. Su descripción corresponde al capítslo de fiestas gänaderas.

Capinos.- Después de las ovejas, las caibras o chivatos constituyen otra de las riouezas de los lupinos. Entre 10 a 200 las posee cada familia. Son animales que pueden ser aimentados fácilmente, comen cualquier yerba del monte, excepcionaineate jos lievan a pastar a algún alfalfar. Se guardan junto con las ovejas y vacas en là entrada del puebio. Son muy "dañeros y lo único dificil en su crianza es el cuidádo que debe desplezarse para evitar oue se metin en los campos cultivados, cuando sucede esto los pleitos son serios. Las demandas llegan hasia donde ei Juez de Paz. Los chicos de prelerencia son los que pastean los chivatss. Salen diarianterite con su fiambre en su "nunko" que "esJunae Rleguilaebli uro pañalo "visjo gransts de los que usan las mujeres, llevar cancha y queso, alsunas veces papas; van con su guaraca para arrearlos. Nunca los llevan a pastar en gran cantidad a lugares fuera de la Comunidad.

De los chivatos aprovechan su carne, leshe y pollejo. Un chivato cuesta entre 10 a 12 soles en el pueblo y enire 15 a 18 soles en Lunahuaná o Cañete. La carne preferida es dęi chivato "orko" (macho), la usan especialmente para preparar el "seco". El despelleje y muerte de un chivato es similar al de la cveja. El pellejo se usa para hacer "tinyas", pero su consumo es pequeño, más se guarda y lleva a vender a Huancayo, a las curtiembres. La ieche de las cabras la utilizan las personas enfermas, especialmente del pulmón, y cuando los tupinos que regresan del servicio militar, en Lima, o de un largo viaje a la costa, sus familiares les dicen "debes estar muy débil" y diariamente les dan leche de cabra, pues piensann que es nuy nutritiva. Los niños cuando están en exámenes la toman. También la usan en mazamorra que es el plato favorito de muchas femilas; hasea hervir la le- 
che con harina, canela y azúcar hasta que tenga punto. El ordeñe es en las mañanas y tardes, dos veces al día, y se realiza en el corral, por mujeres y hombres. Cuando la cría tiene cinco meses los separan de su madre para dormir en Iugares especiales y las juntan después de haberlas ordeñado, antes no es posible hacerlo. Hacen queso de leche de cabra, con el mismo procedimiento que emplean para hacer el queso de vaca, sclimente que los moldes son imás pequeños. La cabeza, sancre, patas y todas las vísceras interiores, no las usan para nada. Solamente la carne se aprovecha, de preferencia en "seco", con arroz y papas; y con culantro, ajos molidos y aí de color, como condimentos. No hacen nunca caldo de esta carne.

La sarna es la principal enfermedad de los ohivatos. También cuando comen hueso de otros animales les dá el "umamuyo" el animal deja de comer, se ent́lapuece y actúa como si estuviera borracho. Sufren mal parto cuando los chivatos machos pisan a las hembras que están preñadas. Los fetos se botan. Cuando comienzan las lluvias empieza la śposa de ceio en los chivatos y el hecho de hacer gran bullicio, es anuncio de lluvia a los habitantes. La preñez dura cinco meses. Paren cos veces ai año. Cuando nacen mellizos es de buena suerte para el dueño, significa buena cosecha. Todas las familias tienen perros que cuidan estos animales; cuando una persona extraña se acerca a tocarlcs no lo permiten, Clos Guuerden, IeSllaman "michikos" o cabreros.

\section{"Jorge Puccinelli Converso"}

Pira negocio se castra a los chivatos a fin de que engorden.

Para curar sus enfermedades les hacen tomar agua con sal cuando estén enfermos por haber comido huesos; la sarna la curan con sebo hervido. Las Juxaciones se tratan igual que en las ovejas.

Hay herranzas de cahras en la nisma fecha que las ovejas. Hay mísica y tono especiaj de valtataki, para estas fiestas. No se toma la sangre ni se marca, solamente se les corta la oreja y pone la señal.

Arimales de carga y transporte.- Los burros son usados únicamente corno animales de carga. Los mulares y caballares como carga y transporte. Muchas personas poseen estos animales por su gran util:dad, de prefeiencia los crían aquellos que se dedican al cemercio y tienen tiendas en el pueblo. Ceida uno de estos tiene entre dos - tres burros y cuando menos dos mulas y caballos. Para el transporte las mulas son las mejores y no están herradas, así como tampoco lo están los cabalios. A pesar de tener animales para montar no los utilizan, prefieren, cuando viajan, llevar en ellos sus alforjas. Unos a otros se alquilan los animales cuando necesitan transportar sus cose- 
chas o viajar a la costa. Llevan en sus burros cargas de 4 a 5 arrobas hasta Lunahuaná y Cañete, las mulas cargan más, de seis a ocho arrobas. Denominan "cargueros" a todos los animales que sirven para cargar y "caballerías" a los que utilizan para montar. Una mula cuesta entre 300 á 400 soles, un cáballo de 300 a 200 soles y los burros de 80 a 150 soles, estos los compran de Cachuy y cuando una burra tiene crías las venden entre ellos.

Cuando estos animales hacen "daño" o sea comen un terreno cultivado, el Agento Municipal o e! interesado los lleva al "coso", situado -en el costado sudceste del pueblo, un cerco de piedras de $1.80 \mathrm{~m}$. de alto, que tiens una puerta de madera con'candado. Ahí permanecen hasta que el dueño los reclama, entonces tiene que pagar la multa respectiva al Concejo, un sol por día y al perjudicado, por el valor del "daño".

El alquiler de una "caballería" de Tupe a Catahuasi o viceversa cuesta cinco soles y de un "carguero" tres soles.

En la agricultura estos animales son utilizados, para traer las cosechas de los lugares sembrados, que están situados a la vera de los caminos. La cosecha de Aiza es traída en burros, caballos y mulares. $\mathrm{Su}$ uso se reduce únicamente al transporte de las cosechas en estos casos.

Los animales mấs apreciados sonelas mulas por su resistencia, tanto para cargar comor para caminar por sitios difíciles. Para ello son muy buenos y cuando los montan les tienen "gran confianza. Nunca galopan a sus animales de transporte. Los caballos cuando están chicos los amansan, existen algunos amansadores en el pueblo y lugares vecinos a los cuales contratan. Son los entendidos. A los tres años generalmente comienzan a amansar tanto a las mulas como a los caballos.

Algunos de estos animales tienen su nombre. Los marcan con las iniciales del dueño, cuando hacen las herranzas de los vacunos o indistintamente y lo hacen para que no se pierdan.

No existen corrales especiales para ninguno de estos animales y no los hacen pastar exprofesamente, cuando no los usan los llevan a sus alfalfares lejos del pueblo y ahí los dejan. Pero siempre bajo la vigilancia de sus dueños. Especialmente los burros son cuidados porque los pumas tienen la especialidad de devorarlos. En las noches los atacan y se les prenden al lomo destrozándoles el pescuezo. Cuando está muerto lo desgarran y solamente les gusta comer su corazón. En una noche pueden matar hasta tres de estos animales. 
Cuando los necesitan para alqún viaje, los llevan en la víspera a su casa y en la puerta o la pampa de "shusho" los hacen dormir, en la mañana, les dan alfalía o chala en abundancia antes de emprender el largo viaje. Durante las pascanas del viaje se preocupan de alimentârlos y antes que ellos buscan refugio y comida para sus animales. No les quitan sus aparejos cuando llegan a un lugar, después de un viaje de muchas horas, porque pueden enfermar, esperan que les pase el cansancio y dejen de sudar, se "resirian y pueden morir", dicen. Los aparejcs de un "carguero" son los siçuientes:

1. Un sobrepelo, que es de jerga, costal o poncho, 2. Cuatro pollejos de camero, 3. Un lomillo de lotora, que se compra en Chincha, 4. Un pellejo o costal, 5. La cincha, que es de lana de oveja, alpaca o de "shampakara". Es tejido, en sus puntas tiene dos argollas.

Sobre la cinchi se coloca !a carga, en alforja o en arco. Se tercia o amarra con sogas: compradas en ta costa, reatas hechas en el pueblo de cuero de váca o con scogas de "shampakara". Pára bajar sa amzrra pasando por la barriga, llampinduse a esto "cinchada en tres costillas". Para subir se amarra adelante

Los aparejos do las "caballerías" son:

1. Un sobrepelo, 2. Nos o tres caronas ojue pueden ser frazadas, ponchos viejos o costales, 3. Una sobrecarona de cuero curtido de res, comprado en las talabarterías de bimal a Huancaye, 4. La montura, comprada en Lima o Huancayp con sus cinchas, 5 . Las estribos, 6. la rienda, 7. el tapa-ojo, 8 . el ffeno o brian,vegs là falsa rienda que se amarra al hocico.

El sobre pelo, caronas, cinchas, sogas, son hechas en el pueblo por sus respectivos dueños.

Muchas personas tienen bridas, riendas y estribos de plata.

El muermo y la gusanera en las patas, son las principales enfermedades de las "ca,ballerías". El muermo se cura con una dosis de sulfato de soda con orines calientes. La gusanera la curan con ácido cítrico.

A los burros les afecta la garrapata y piojera. La garraparta se-cura con "konto" molido, con el cual se jes frota. Igualmente la piojera. El "konto" es una hierba medicinal.

CERDOS.- Los chanchos son criados no para comerlos sino para su venta. No tienen cuidados especiales, generalmente están sueltos en los campos cercanos al pueblo y duermen cerca a las casas, no teniendo lugares especiales. Los alimentan con chalas, cáscaras de par pas pero corno andan sueltos hay poco cuidado en lo que comen. A 
los machos los castran para que engorden, a fin de cebarlos. Hay en el pueblo varios hombres que capan a los chanchos y cobran según la amistad con ol dueño: suarenti centavos a un sol. Para castralos buscan una cucinilla que no haya sido usada a fin de evitar la infección, amarran al chancho y tumbado le hacen un tajo en los testes para sacarlos. Es ayudado por otras personas. Una vez castrado le echan ceniza y los días siguienies los curan con orines calientes.

Cuando maian ur chancho, lo hacen después de haberlo engordado, para ello lo cehan dándole maíz, caldo de hueso, calabaza, cebada molida y los tienen guardados en una pirca cerca de su casa. En la pirca los tienen escondidos procurando que nadie los vea, porque si alguien los ve dicen: "que chancho tan gordo, seguro que lo van a matar" y creen que el chancho al oir esto enflaquece. Para matarlo le abren un agujero, cerca del homoplato, luego con una caña le hincan por ese hueco el corazón. Utilizan la carne para chicharrón y manteca. De la sangre hacen "lunganishe" o sea relleno. La manteca la depositan en latas y la guardan en sus cassas, vendiéndola por cucharadas y solamen. te a sus familiares o amigos. Cada cuciarada vale 0.20 centavos. Muy pocas familias tienen cerdos. En Aiza se dedican más a lai cría para su venta en la costa.

Un chancho cebado y castrado vale entre 80 y 90 soles. Chicos cuestan 10 a 20 soles.

Gallinas y cuyes.-.. Las gallinas no son criadas en gallineros especiales, duernien ${ }^{\text {en }}$ los rimeros de leña que existen al lado de las casas. No se les da cuidados especiales y las dejan caminar por todo el pueblo. Las crían para venderlas o cambiarlas por productos, a los costeños que vienen al pueblo. Sus huevos los comen aquellos que tienen vacas, en lugar del queso, por el resto es considerado como lujo. La gallina en kauke es "uallpa", el gallo, "orko" y los pollitos 'chiuches". Una gallina cuesta entre 10 a 12 soles. Los huevos a 20 centaivos cada uno. Los alimentan con maíz y desperdicios. Para matar una gallina le tuercen el pescuezo con la mano. La sangre y todas las vísceras son para los perros. Ellos nunca las comen. Los pollitos no reciben tampoco ningún cuidado especiát. Carecen de gallinas finas. Matan las gallinas en fiestas o alguin santo.

Los cuyes existen en pequeña cartidad, poseyéndolos algunas familias, nunca los comen, solamente los utilizan para "brujeria". Para sobar el cuerpo de alçuna persona gue está enferma de susto o que sufra de algún "daño". Una vez frotado el cuerpo de la persona tratadä., el animal es enterrado en una chacrai, generalmente el lugar don- 
de se ha asustado, golpeado o caído, lo adornan con flores, y lo entierran con pasas, frutas, flores y le echan encima "uksa".

Perros y gatos.- Los perros (xal'kos), son criados para el cuidado de los animales, los rebaños y la casa. Cada familia por lo menos tiene dos o tres perros. Todos son de raza chica y chusca. Venden las crías entre 30 a 50 centavos cada una. Cuando una persona se acerca a una "punta" de ganado y trata de agarrar uno de ellos, los perros embisten inmediatamente a la personai no dejándola acercar. Todos tienen nombres: Galgo, Cariñoso, Bocanegra, Chuko, Aviador (porque tienen rayas en sus patitas), Koroke, Vilche, Mistiko (el que es cariñoso con los animales que cuida), Codito, etc.

Los gatos "mishe", son muy apreciados y cada familia tiene dos - tres, les sirven para que cazen los pericotes que abundan mucho en sus casas y que causan perjuicios en los depósitos de víveres. Un gato chico vale cinco soles. Los blancos son los preferidos. Tienen nombres, generalmente a las hembras las llaman "Josefina" y al macho "Pedrito".

SOCIEDADES GANADERAS.- Existen en el pueblo sociedades ganaderas quie tienen sus Estatutos y Acuerdos como las Sociedades Religiosas. Llaman a éstas "Sociedades Económicas y de ayuda y đłuxilios mutuos". De cercå de 30 -sociedades que tenemos registradas, la tercera parte están perfectamente organizadas, el resto no son sociedades, sino simplemente clurupaciones.

Varios dueños o herederos de una determinada zona de tierra, generalmente situada en la parte alta de la quebrada de Tupe, en el límite entre la propiedad privada y la comunall, se agrupan y deciden formar una sociedad, hacen su acta de fundación, nombran a una persona a que confeccione su Estatuto y luego de aprobarlo se ciñen a él. Lạ agrupación tiene por objeto hacer un cerco común a sus propiedades para dejar que crezcan los pastos naturales con las lluvias y cuando ellas terminen y escasee el pasto en la parte baja de la quebralda, tenerlo en sus cercos que están reservados. Es una forma de previsión.

En el pueblo estas aọrupaciones son conocidas con el nombre de "Cerco de....." (nombre del lugar), y no de Sociedad que indican en sus documentos. Todos los años y durante la época de lluvia trabajan en común arreglando el cerco, en algunos cercos se permite cultivar trigo y cebada o papas. Cuando el pasto está crecido y maduro se hace el "corte" 0 sea que se permite el ingreso al ganado. Para esto hacen su 
"acuerdo" en la víspera, en casa del Presidente de la sociedad, ahí discuten durante toda la noche sus cuentas, bailan "vakataki" y toman "chamiscol". Las mayores discusiones en estas reuniones son por las "fallas", o sea el pago que deben dar a la Sociedad aquellais personas que no cumplen con sus obligaciones. Muchos se resisten a pagarlas. Una vez designadas las familias que deben gozar el cerco ese año, fijan la cantidad de animales que cada heredero o familia debe llevar al cerco, por ejemplo, indican como máximo para cada uno de los interesados seis vacas, por cada una de más que lleven deben de pagar un sol como mulia. El dinero recaudado por concepto de "fallas" es repartido entre las personas que han cumplido con todos los trabajos, y en esa repartición muchas veces consideran que el trabajo de una mujer en la quinchada de un cerco no es igual al de un hombre y reparten a un hombre el doble de lo que le dan a una mujer.

Todos los tupinos, hombres y mujeres, pertenecen por lo menos a cuatro o cinco cercos, los que más a diez o doce. Los principales cercos son:

1 Manchay, 2 Pinkillatnusho, 3 Pallka, 4 Huacracocha, 5 Pitutaya, 6 Cahualcuncha, 7 Chik-lla, 8 San Francisco, 9 Shuskala, 10 Uakúaichusko, 11 Kus'h-pirka, 12 Añipuanka, 13 Murmuro, 14 Chaichime, 15 Mallma, 16 Patamailla, 17 Chumpa, 18 Pinta, 19 Ish-kirkaka, 20 Huanturo, 21 Kinsirpampa, 22 Kallpampa, 23 Chiure, 24 Uip-kire, 25 Nahuimpuquio, 26 Suiio, 27 Napsite, 28 Magdalena, 29 Kiske-shuinko.

Todos los asociados están en la obligación de trabajar en la mejora o arreglos del cerco, los interesados que no asistan a estos trabajos son multados y débengpagar sur'qalla" segun seuerdo de la Sociedad, dos o tres sciles, tasancio el trabajo realizado se fija el monto de la "falla". Cuando se realiza un trajbajo compran con el dinero de las "fallas" alcchol, coca, cigarros y fósforos, los cuales son repartidos a los que concurren al trabajo.

Las Sociedades tienen entre 10 á 20 familias como socios, además de los herederos, en caiso de muerte de algún miembro.

Antiguamente los cercos pertenecían a dos o tres dueños y por herencia han ido aumentando hasta tener ahora muchos dueños. Cada uno de esos troncos a la fecha, ha dejado entre 40 á 50 herederos. Cuando se arriendal un cerco, por acuirdo, en 300 ó 400 soles, resulta que a cada interesado le corresponde 2 ó 3 soles. Este dinero lo pueden cobrar o dejar en "giro" o sea préstamo a los socios que lo soliciten, a un determinado interés anual, 10 á $20 \%$. Esto constituye el 
Cápital de cada uno de ellos y la Sociedad es lal encaragada de administrarlo. Muchas mujeres tienen su dinero en "giro".

Uno de los cercos, cuyo estatuto hemos copiado, fué fundado el 4 de junio de 1937. En su acta de fundación manifiestan que la Sociedad debe ser "abrigada" por un Presidente, Secretario, Tesorero y dos vigilantes 0 vocales: Nombraron a una persona para que redactara sus Estatutos. A los 5 meses, en noviembre de 1937, esta persona remitió con un oficio el Estatuio redactado el cuial fué aprobado. Este Estatuto de lã "Seciedaci Auxilios Mutuos" del Cerco de Manchay, tiene 23 capítulos, cada uno de ellos con su lítulo respectivo. l'odos los documentos y libros que tiene cada sociedud son legalizados por el Juez de Paz. La Sociedad de Manchay tiene un libro de Áctas de 20 páginas, 1 libro de cuentas de 200 páginas; 35 legajos de cuentas y relaciones $Y^{\prime}$ 26 dccumenios en pagaré. Tiene 31 socios y 5 grupos de herederos.

Este cerco fué arrendado a un tupino este año en 485 soles.

Como este cerco hay unos 8 a 10 perfectamente organizados; el resio funciona como lo hacían antiguamente; sin estatutos, ni directivas, los interesados 0 dueños hacen sus arreglos y trabajos anualmente y en casa de uno de ellos designan a los que deben usifructuarlos.

Según los Estatutos, los cercos dejen ser mejorados cada año y las acequias limpiadas. En la "limpia de la acequia" debe abonar cada uno 10 centavos para celebrar el responso de las almas. Designan, asimismo, los Capitanes, Mayordomos y Mayoralas para esta fiesta, los primeros deben proporconat una botalla de aguardiente, buen café, traer pito, tambor y bandera. Los mayordomos deben dar una botella de aguardiente, una cajetilia de cigarros y fraer una corneta. Las mayoralas dan un cuarto de aguardiente, enflorarán a todos los socios y adornarán con flores "selectas" la cruz que existe en la toma. Los socios Jue tengan ura conducta "inmoral o perriciosa en la sociedad" serán expulsados y los que defrauden dinero a la Sociedad "serán terminantemente arrojados". Cada dos años se debe poner en remate el cerco con el fin de incrementar los fondos de la Sociedad. Los socios que abandonen el cerco, pagarán una multa de cinco soles por cada año. Todos los socios pueden llevar dinero de la Sociedad en "giro" pagando $20 \%$ o menos como interés anual. Allgunas Sociedades tienen en su Junta Directiva un Juez de Aguas. Siempre el Presidente es considerado como la única autoridad. Cada uno de los miembros de la Junta Directiva, tiene sus atribuciones perfectamente delimitadas. Los fondos de lal Sociedad son: los productos de los arrendamientos de los pastales, los pagos por abandono y todas las multas recaudadas. Los 
"goces de la Sociedad" son: en caso de muerte de algún "hermandad" (interesado) la Sociedad debe proporcionar un ataud, la mortaja y dos libras de cera, o en su defecto deberá "cancelar en oro efectivo el valor del goce mencionado"; deben acompañar el traslado de sus restos ai cementerio y los que no asistan pagarán un sol de multa. Sobre lèss votaciones indican que serán públicas, poniéndose de pié, y secretas, por medio de ánforas. Los socios son los interesados, comenzando desde el tronco a los tataranietos y "no deben ser impediso ni heredero ilegítimos". Pueden haber socios honorarios y portectores.

El capítulo referente a Ganadería se complementa con el relato de las Fiestas Ganaderas que por su extensión no es posible incluírlo en este artículo.

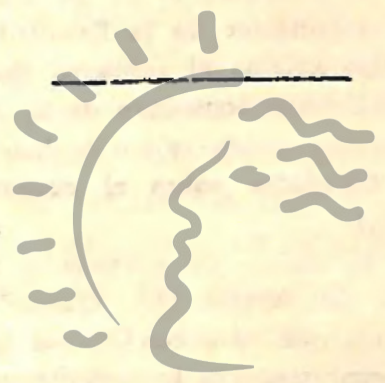

\section{Biblioteca de Letras}

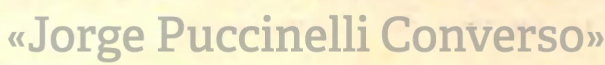

